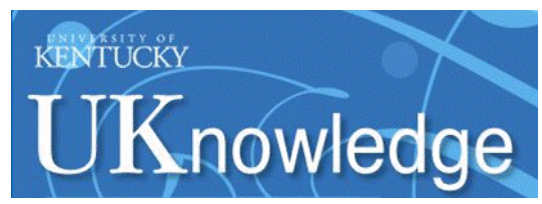

University of Kentucky

UKnowledge

\title{
Socioemotional Selectivity and Psychological Health in Amyotrophic Lateral Sclerosis Patients and Caregivers: A Longitudinal, Dyadic Analysis
}

\author{
Suzanne C. Segerstrom \\ University of Kentucky, segerstrom@uky.edu \\ Edward J. Kasarskis \\ University of Kentucky, edward.kasarskis@uky.edu \\ David W. Fardo \\ University of Kentucky, david.fardo@uky.edu \\ Philip M. Westgate \\ University of Kentucky, philip.westgate@uky.edu
}

Follow this and additional works at: https://uknowledge.uky.edu/psychology_facpub

Part of the Biostatistics Commons, Neurology Commons, and the Psychology Commons

Right click to open a feedback form in a new tab to let us know how this document benefits you.

\section{Repository Citation}

Segerstrom, Suzanne C.; Kasarskis, Edward J.; Fardo, David W.; and Westgate, Philip M., "Socioemotional Selectivity and Psychological Health in Amyotrophic Lateral Sclerosis Patients and Caregivers: A Longitudinal, Dyadic Analysis" (2019). Psychology Faculty Publications. 197.

https://uknowledge.uky.edu/psychology_facpub/197

This Article is brought to you for free and open access by the Psychology at UKnowledge. It has been accepted for inclusion in Psychology Faculty Publications by an authorized administrator of UKnowledge. For more information, please contact UKnowledge@lsv.uky.edu. 


\title{
Socioemotional Selectivity and Psychological Health in Amyotrophic Lateral Sclerosis Patients and Caregivers: A Longitudinal, Dyadic Analysis
}

\author{
Digital Object Identifier (DOI) \\ https://doi.org/10.1080/08870446.2019.1587441 \\ Notes/Citation Information \\ Published in Psychology \& Health, v. 34, issue 10. \\ Copyright @ 2020 Informa UK Limited
}

This is an Accepted Manuscript version of the following article, accepted for publication in Psychology \& Health. Segerstrom, S. C., Kasarskis, E. J., Fardo, D. W., \& Westgate, P. M. (2019). Socioemotional selectivity and psychological health in amyotrophic lateral sclerosis patients and caregivers: A longitudinal, dyadic analysis. Psychology \& Health, 34(10), 1179-1195. https://doi.org/10.1080/ 08870446.2019 .1587441 It is deposited under the terms of the Creative Commons AttributionNonCommercial License (https://creativecommons.org/licenses/by-nc/4.0/), which permits noncommercial re-use, distribution, and reproduction in any medium, provided the original work is properly cited. 
Published in final edited form as:

Psychol Health. 2019 October ; 34(10): 1179-1195. doi:10.1080/08870446.2019.1587441.

\title{
Socioemotional selectivity and psychological health in amyotrophic lateral sclerosis patients and caregivers: A longitudinal, dyadic analysis
}

\author{
Suzanne C. Segerstrom, \\ University of Kentucky \\ Edward J. Kasarskis, \\ Department of Neurology, College of Medicine, University of Kentucky \\ David W. Fardo, \\ Department of Biostatistics, College of Public Health, University of Kentucky \\ Philip M. Westgate \\ Department of Biostatistics, College of Public Health, University of Kentucky
}

\begin{abstract}
Objective-Socioemotional selectivity theory predicts that as the end of life approaches, goals and resources that provide immediate, hedonic reward become more important than those that provide delayed rewards. The present study tested whether these goal domains differentially affected psychological health in the context of marital dyads in which one partner had been diagnosed with amyotrophic lateral sclerosis (ALS), a life-limiting disease.
\end{abstract}

Design-ALS patients $(\mathrm{N}=102)$ being treated in 3 multidisciplinary clinics and their spouses ( $\mathrm{N}$ $=100$ ) reported their loneliness, financial worry, and psychological health every 3 months for up to 18 months.

Main Outcome Measure-Psychological health composite.

Results-In multilevel dyadic models, patients and spouses had similar levels of financial worry and loneliness. Both patients and spouses had worse psychological health with higher loneliness, but only spouses had worse psychological health with higher financial worry. Significant interactions with age and disease severity indicated that older spouses were more affected by loneliness than were younger spouses, and patients with less severe disease were more affected by financial worry than patients with more severe disease.

Conclusion-The results provide good support for socioemotional selectivity theory's implications for psychological health in a strong test of the theory.

Corresponding author: Suzanne C. Segerstrom, Department of Psychology, University of Kentucky, 125 Kastle Hall, Lexington, KY 40506-0044, Phone: 859-257-4549, segerstrom@uky.edu.

Declaration of Interests

The authors have no conflicts to declare. 


\section{Keywords}

married couples; ALS; loneliness; depression; socioemotional selectivity

As people age and their time remaining in life decreases, their goals, motivations, and values shift toward close social relationships and positive emotional experience and away from relationships and resources that are more closely aligned with status and knowledge (Carstensen, Isaacowitz, \& Charles, 1999). Socioemotional selectivity theory predicts that such shifts are adaptive insofar as they maximize resources that can be realized immediately (e.g., meaning in life, positive affect, and social connection) over resources that will be important in the future or that take time to develop (Carstensen, Fung, \& Charles, 2003; Fung \& Carstensen, 2004; Riediger, Schmiedek, Wagner, \& Linderberger, 2009).

Socioemotional selectivity has been extensively documented; however, there are few tests of its adaptiveness, especially with regard to social selectivity. The present study tested whether concerns about social and financial resources in people with a life-limiting disease amyotrophic lateral sclerosis (ALS) - were differentially associated with psychological health. The effect of decreased time remaining in life was isolated from other demands of ALS by comparing people with ALS and their spousal caregivers.

The sense of limited time remaining in life can arise from aging or from a life-limiting disease, both of which may refocus motivations and values. ALS causes progressive deterioration of upper and lower motor neurons, ultimately resulting in complete paralysis, respiratory weakness, and either death or continuous mechanical ventilation. The disease is more common in men than in women and is associated with older age, with peak incidence between ages 50 and 75 . ALS is a life-limiting disease, with typical survival of 3-4 years after onset (van Es et al., 2017).

Life-limiting diseases including HIV (before highly active antiretroviral therapy increased life expectancy) and advanced cancer have been associated with socioemotional selectivity. Compared with asymptomatic HIV seropositive or HIV seronegative gay men, symptomatic HIV seropositive men assigned more importance to the potential for positive interaction with social partners and less importance to potential for 'getting to know' novel social partners. The three groups had similar chronological age (Carstensen \& Fredrickson, 1998). Similarly, patients with heterogeneous cancers showed a greater preference for a hypothetical familiar over unfamiliar social partner compared with healthy controls (Pinquart \& Silbereisen, 2006). Women with metastatic breast cancer and age-matched healthy controls had similar numbers of goals related to spending time with close others. However, women with cancer had more goals related to enjoying the present and maximizing emotional satisfaction and fewer goals related to planning for the future. This goal shift was more pronounced the longer the woman had been diagnosed with metastatic disease (Sullivan-Singh, Stanton, \& Low, 2015, Study 1).

This and other evidence support socioemotional selectivity in older age and with lifelimiting disease. However, individual differences in the degree of socioemotional selectivity might affect psychological health, consistent with the prediction that socioemotional selectivity is adaptive. First, socioemotional selectivity is predicted to allow people to derive 
the greatest psychological benefit from the present by yielding more positive affect and meaning in life. Supporting this mechanism, when women with metastatic cancer had goals related to less limited time (i.e., contrary to expected socioemotional shifts), they reported less personal growth over time. When they had goals related to more limited time (i.e., consistent with expected socioemotional shifts), they reported fewer intrusive thoughts about cancer (Sullivan-Singh, Stanton, \& Low, 2015, Study 2). To our knowledge, only this study has tested the adaptiveness proposition of socioemotional selectivity theory.

A second mechanism concerns how well people are progressing toward their goals. In general, progress toward or achievement of more important goals affects psychological health to a greater degree (Emmons, 1986; King, Richards, \& Stemmerich, 1998; McGregor \& Little, 1998; Segerstrom, Jones, Scott, \& Crofford, 2016). Goals and resources might differentially influence psychological health in the context of life-limiting disease based on their place in socioemotional selectivity theory. For example, the goal of sustaining close social relationships, which is normatively more important toward the end of life, might affect psychological health to a greater degree for older people than for younger people. However, such differential effects have not been examined in people who expect differing amounts of time remaining in life.

The adaptiveness proposition of socioemotional selectivity theory implies how stress reduction might be implemented - and implemented differentially - for patients with lifelimiting disease and their spouses or other caregivers. Interventions in this context are often focused on coping with the disease, the demands of caregiving, or both (Meyer \& Mark, 1995; Sörensen, Pinquart, \& Duberstein, 2002). Interventions further tailored to maximize resources in the socioemotional domain that best fits the individual could further improve psychological health for both dyad members. Furthermore, psychoeducation about why patients and spouses or caregivers might have different priorities and goals could reduce dyadic conflict.

Dyads in which one partner has been diagnosed with ALS provide a valuable context in which to study socioemotional domains and their psychological consequences. Following from the effects of ALS on time remaining in life, first, patients' goals and values should be aligned with close social resources to a greater degree than spouses'. Second, because close social resources should be more important to patients, concerns in that domain should affect them to a greater degree than spouses. The dyadic context provides for a strong test of these predictions. There are dyadic similarities in psychological well-being in ALS patients and caregivers (Garcia et al., 2017; Rabkin, Wagner, \& Del Bene, 2000). ALS disease progression can impact some aspects of caregivers' quality of life to a greater degree than patients' (Gauthier et al., 2007; Roach, Averill, Segerstrom \& Kasarskis, 2009). Both members of the dyad are affected by ALS, but only patients are confronting the possibility of their own premature mortality. Therefore, comparing dyad members allows for isolation of the effect of time remaining in life from other aspects of ALS that affect both members of the dyad, such as general awareness of mortality, changes in life circumstances, and diseaserelated stress. 
Finally, within dyad membership (patients or spouses), there are individual differences that could influence the effects of socioemotional goals. Older spouses might be similar to patients in their socioemotional goals and the psychological consequences thereof because they are also approaching the end of life, and patients with less severe disease might be more similar to spouses because they are farther from the end of life (cf. Carstensen \& Fredrickson, 1998).

The present study investigated the relationships between social and financial concerns and psychological health among patients and caregivers in the Seattle ALS Patient Profile Project (McDonald et al., 1994). In this multi-site study, patients and caregivers were interviewed in their homes repeatedly over approximately 18 months, allowing for examination of both stable individual differences and change over time in social and financial concerns and psychological health. Social concerns were operationalized as loneliness. Loneliness is distinct from social isolation per se in that it reflects a discrepancy between personal goals or expectations for social connection and experienced social connection (Rook, 1984). Perceived deficits in close relationships result in loneliness to a greater degree than do perceived deficits in casual relationships (Routasalo, Savikko, Tilvis, Strandberg, \& Pitkälä, 2006; Russell, Cutrona, McRae, \& Gomez, 2012). Therefore, loneliness reflects concern about the type and quality of social relationships that socioemotional selectivity theory predicts become more important as the end of life approaches (Carstensen, Fung, \& Charles, 2003). The effects of loneliness were contrasted with financial concerns, operationalized as worry about having enough money to meet financial needs. Financial worry is a future-oriented concern about the adequacy of a nonsocial resource and therefore should become less important as the end of life approaches.

The hypotheses were tested in dyadic longitudinal models, which consider couples as an 'interdependent relational system' confronting disease over time (Lo et al., 2013), explicitly modelling the degree to which dyads are similar to each other both on average and as they change over time (Laurenceau \& Bolger, 2013). The following hypotheses were tested:

1. Accounting for dyadic similarity, patients will have higher social concern (loneliness), and spouses, higher financial concern (worry about finances). This prediction follows from the expected relative importance of social and financial goals among patients and spouses.

2. Accounting for dyadic similarity, patients' psychological health will be more affected by social concerns, and spouses', by financial concerns. This prediction arises because resources and goals that are important to or valued by the individual have greater impact on psychological health than those that are less important or valued.

Exploratory analyses tested interactions between concerns and age (among patients and spouses) and disease severity (among patients). 


\section{Method}

\section{Participants}

Participants were 102 patients with ALS and 100 spousal caregivers from the Seattle ALS Patient Profile Project. The analytic sample was a subset of the total sample (N = 143 patients and 123 caregivers). There were 103 spouse-patient dyads in the study (20 patients had no caregiver in the study; 20 had another family member or paid caregiver in the study). One patient-spouse dyad and two spouses were not included in analyses because they were missing all financial worry or loneliness data. Demographic characteristics of the final analytic sample are shown in Table 1. Inclusion criteria (as reported by McDonald et al., 1994) were neurologist-confirmed diagnosis of ALS and ability to communicate in English. Exclusion criteria were dementia diagnosis and 'known' alcoholism.

Patients with spouses in the study were less lonely at baseline than patients with other caregivers or no caregiver in the study $(\mathrm{M}=7.5$ vs. $\mathrm{M}=8.3, \mathrm{t}(140)=2.09, p=.038)$ and more likely to be male $\left(\chi^{2}(1)=8.9, p=.003\right)$ but were not significantly different on other demographic or study variables. Spousal caregivers were more hopeless than other caregivers $\left(\mathrm{M}=5.1 \mathrm{vs.} \mathrm{M}=3.2, \mathrm{t}\left(45.5^{1}\right)=2.7, p=.01\right.$ ) but were not significantly different on other demographic or study variables.

\section{Procedure}

Patients were recruited from ALS clinics and support groups at 3 sites (Seattle, WA; San Francisco, CA; and Philadelphia, PA). They were interviewed every 3 months in their homes for up to 18 months, responding to a number of standard questionnaires as well as studyspecific questions. The University of Washington Human Subjects Committee provided approval for the study, and all participants provided informed consent. Data were collected between March 1987 and August 1989.

There were 925 person-interviews available for analysis (481 for patients and 444 for spouses) from the maximum of 1,414 (202 people $* 7$ interviews). Missing data were due to patient death before the end of the study (171 and 166 person-interviews missing for patients and spouses, respectively), early withdrawal from the study (43 and 77 person-interviews), or unexplained missing data (19 and 13 person-interviews). Figure 1 shows the reasons for missingness at each interview.

\section{Measures}

Measures were selected that (1) were asked of both patients and spouses in the same way at every interview, (2) had reasonable distributions (i.e., no ceiling or floor effect), and (3) had sufficient variability between and within people to test relationships with psychological health at both levels. The following measures met those criteria as well as being substantively parallel in that they represent concern about the respective domain.

\footnotetext{
${ }^{1}$ Equal variances assumption rejected and corrected statistic used.
} 
Financial worry-Financial worry was measured with a single item asked of both patients and spouses about how much worry he or she was currently experiencing over having enough money to meet financial needs. They responded on a scale of $1=$ no worry to $10=$ extremely worried. The intraclass correlation (ICC) for patients was .67 and for spouses was .66, indicating that about two-thirds of the variance in financial worry was stable (between people) and one-third was changing (within people).

Loneliness-Loneliness was measured with the 4-item survey version of the UCLA Loneliness Scale (Russell, Peplau, \& Cutrona, 1980). Items refer to feeling 'in tune' with others, feeling understood, and having enough companionship. This version had adequate internal consistency in the validation sample $(a=.75)^{2}$. The ICC for patients was .48 and for spouses was .56, indicating about half of the variance in loneliness was stable (between people) and half was changing (within people).

Psychological health-To provide a broad operational definition of psychological health, both patients and spouses were characterized using a composite of scores on the Beck Depression Inventory, the Beck Hopelessness Scale, and the Perceived Stress Scale (Beck, Steer, \& Carbin, 1988; Beck, Ward, Mendelson, Mock, \& Erbaugh, 1961; Beck, Weissman, Lester, \& Trexler, 1974; Cohen, Kamarck, \& Mermelstein, 1983). Collectively, these scales include items reflecting psychological health in both the affective domain (e.g., sadness, anger, anxiety) and the cognitive domain (e.g., expectancies, control). All scales had adequate reliability and validity in validation samples. ICCs for the individual scales in patients ranged from $.58-.78$ and in spouses, from $.63-.78$. Therefore, most of the variance in psychological health was due to stable individual differences, with about a quarter of the variance due to within-person changes over time. Correlations among the 3 scales between and within people indicated that they were sufficiently related to each other to create a psychological health composite. For patients, between-person correlations among the scales were $.53-.63$ and within-person correlations were $.43-.46$; for spouses, between-person correlations were $.49-.69$ and within-person correlations were $.14-.45$. Mean (SD) patient BDI score (as mean across all interviews) was 13.3 (6.7), spouse, 9.3 (5.6); mean patient BHS score was 7.7 (5.0), spouse, 5.4 (4.1); mean patient PSS score was 24.6 (6.8), spouse, 24.7 (6.4). Patients could therefore be characterized on average as having mild depressive symptoms, hopelessness close to the clinical cutoff (8), and somewhat elevated $(Z=0.66)$ stress; spouses on average as having normal to mild depressive symptoms, normal hopelessness, and somewhat elevated stress $(Z=0.68)$ (Brown, Beck, Steer, \& Grisham, 1989; Cohen \& Williamson, 1988; Kendall, Hollon, Beck, Hammen, \& Ingram, 1987). Therefore, both patients and spouses showed evidence of the demands of ALS on their psychological health but not, on average, severe distress.

The composite was created by converting each scale score to percent of maximum possible (Cohen, Cohen, Aiken, \& West, 1999) and taking the mean of the three scales. Therefore, the composite has a minimum of 0 and a maximum of 100 . Percent of maximum possible is preferred to other methods of standardization (e.g., Z scores) in longitudinal data because it

\footnotetext{
${ }^{2}$ The archival dataset provided scale scores but not individual items, so scale reliability in the sample could not be calculated.
} 
maintains the distributions of and absolute differences in the variables both between and within individuals (Moeller, 2015).

Disease severity-The ALS Severity Scale (ALSS; Hillel, Miller, Yorkston, McDonald, $\&$ Konikow, 1989) total score was used to index disease severity. The score is a sum of functions in speech, swallowing, upper extremities, and lower extremities and has a maximum score of 40. Higher scores reflect better function. Scores above 28 are considered mild disease severity; 17-28, moderate; and lower than 17 , severe.

\section{Data analysis}

Data were analysed in multi-level models with couples at Level 2 and time (interview) at Level 1. Dyadic analysis tested the hypotheses simultaneously for patients and spouses (using SAS [9.3] PROC MIXED with restricted maximum likelihood estimation; Laurenceau \& Bolger, 2013). These analyses use all available observations without listwise deletion.

The dyadic analysis used dummy codes for patient (1/0) and spouse (1/0) to select subsets of the data for estimation of patient and spouse effects. The explanatory variables included financial worry (X1) and loneliness (X2), centred within cluster. That is, each person had a Level 2, between-person variable that was his or her mean across all interviews (superscript $\mathrm{B}$ in the equations below) and represent the effects of individual differences and Level 1, within-person variables that were the deviations from that mean at each interview (superscript $\mathrm{W}$ in the equations below) and represent changes over time. The Level 2 variable was grand mean centred. The time variable was centred around the fourth interview (of 7) so that the intercept represents the average level across the study. For dyads $j$ over times $i$, patients $p$ and spouses $s$ have paired equations:

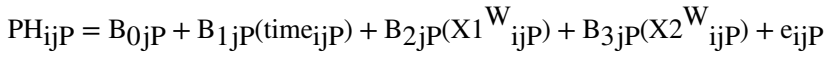

$$
\begin{aligned}
& \mathrm{PH}_{\mathrm{ijS}}=\mathrm{B}_{0 \mathrm{jS}}+\mathrm{B}_{1 \mathrm{j} S}\left(\mathrm{time}_{\mathrm{ijS}} \mathrm{S}\right)+\mathrm{B}_{2 \mathrm{jS}} \mathrm{S}\left(\mathrm{X}^{\mathrm{W}_{\mathrm{ijS}}}\right)+\mathrm{B}_{3 \mathrm{jS}}\left(\mathrm{X}_{2} \mathrm{~W}_{\mathrm{ijS}}\right)+\mathrm{e}_{\mathrm{ij}} \mathrm{S} \\
& \mathrm{B}_{0 j \mathrm{P}}=\gamma_{01 \mathrm{P}}+\gamma_{02 \mathrm{P}}\left(\mathrm{X1}^{\mathrm{B}}{ }_{\mathrm{jP}} \mathrm{P}\right)+\gamma_{03} \mathrm{P}\left(\mathrm{X}{ }^{\mathrm{B}}{ }_{\mathrm{j}} \mathrm{P}\right)+\mathrm{U}_{0 j \mathrm{P}} \\
& \mathrm{B}_{0 j \mathrm{~S}}=\gamma_{01 \mathrm{~S}}+\gamma_{02 \mathrm{~S}}\left(\mathrm{X1}^{\mathrm{B}}{ }_{\mathrm{jS}}\right)+\gamma_{03 \mathrm{~S}}\left(\mathrm{X} 2^{\mathrm{B}}{ }_{\mathrm{jS}}\right)+\mathrm{U}_{0 \mathrm{j}} \mathrm{S}
\end{aligned}
$$

The random effects for patient and spouse intercepts (U) generate a covariance matrix that includes the patient and spouse variances as well as their covariance:

$$
\operatorname{Cov}(\mathrm{U})=\left[\begin{array}{ccc}
a_{P}^{2} & a & P S \\
a_{S} & a^{2} S
\end{array}\right]
$$


Finally, by the likelihood ratio test with mixture degrees of freedom, there were not significant random effects of time. Patients had a random loneliness slope $\left(\mathrm{X}^{\mathrm{W}}\right.$ for patient loneliness; $p=.0056$ ), which was included in the final model. Spouses' random loneliness slope $(p=.046)$ was not included although it was also statistically significant, because its inclusion along with the patient random slope caused estimation and convergence problems with the model.

By dropping either the patient or spouse dummy code, the remaining dummy code represents the difference between patients and spouses. In an example with no predictors, this model becomes:

$$
\begin{gathered}
\mathrm{PH}_{\mathrm{ij}}=\mathrm{B}_{0 \mathrm{j}}+\mathrm{e}_{\mathrm{ij}} \\
\mathrm{B}_{0 \mathrm{j}}=\gamma_{00}+\gamma_{01}\left(\text { patient }_{\mathrm{j}}\right)+\mathrm{U}_{0 \mathrm{j}}
\end{gathered}
$$

$\gamma_{01}$ is recognizable as the unique effect of being a patient (with spouse as reference). This same approach was used to test for the difference between patients and spouses in the effects of explanatory variables.

Sensitivity analysis expanded this model to include gender and study site as covariates. Exploratory analyses included chronological age and disease severity in the model as main effects and interactions with explanatory variables. For significant interactions, simple slopes were estimated and tested by recentring the involved variables around the target values (cf. Aiken \& West, 1991).

\section{Results}

\section{Correlative and descriptive results}

Table 2 shows the correlations among mean (across interviews) loneliness, financial worry, and psychological health for patients (below diagonal) and spouses (above diagonal) as well as correlations with age, gender, and mean disease severity. There were statistically significant correlations between higher loneliness and worse psychological health for patients and spouses and between more financial worry and worse psychological health for spouses. Higher ALSS scores (indicating less severe disease) were also associated with less financial worry and better psychological health among spouses. The modest and not statistically significant correlation between ALSS scores and psychological health in patients is consistent with other evidence that quality of life may not be strongly correlated with disease progression for ALS patients (e.g., Roach et al., 2009).

The first hypothesis was that patients would express more social concern (i.e., loneliness), whereas spouses would express more financial concern (i.e., financial worry). This hypothesis was not supported. In a model with no predictors of financial worry except for the dummy codes for patients and spouses, the intercept for patients $(\gamma=4.72, \mathrm{SE}=0.26$ ) was lower than that for spouses $(\gamma=5.01, \mathrm{SE}=0.25)$; however, this was not a significant difference $(t=0.70, p=0.49)$. These estimates reflect moderate financial worry (i.e., about 
halfway between no worry and extreme worry). For loneliness, the intercept for patients ( $\gamma=$ $7.63, \mathrm{SE}=0.17)$ was lower than that for spouses $(\gamma=8.04, \mathrm{SE}=0.15)$, but this difference was also not statistically significant $(t=1.79, p=.076)$. These estimates are similar to the scale scores for men $(\mathrm{M}=7.24)$ and women $(\mathrm{M}=8.07)$ obtained in population surveys (Silverman \& Kennedy, 1985).

\section{Effects on psychological health}

The second hypothesis was that patients' psychological health would be more affected by social concern (i.e., loneliness) and spouses', by financial concern (i.e., financial worry). This hypothesis was partially supported. Table 3 shows the results of dyadic multilevel models predicting psychological health. Model 1 was an intercept-only model that estimated the average psychological health for patients and spouses. Note that higher scores indicate worse psychological health. The estimate for patient psychological health was significantly worse than that for spouse psychological health $(t=3.32, p=.0013)$. Model 2 included change over time. Patients' psychological health significantly worsened over time $(p=.022)$, and spouses' psychological health tended to worsen as well $(p=.080)$. Patient and spouse estimates were not significantly different $(t=0.89, p=.38)$. Model 3 included the effects of financial worry and loneliness. Among patients and spouses, more loneliness was associated with poorer psychological health both between and within people. Loneliness effects were larger among patients, but not significantly so. More financial worry was only associated with poorer psychological health between spouses. The between-person effect of financial worry was significantly larger for spouses than patients $(t=2.40, p=.018)$. Model 4 included adjustment for study site and gender. All effects of financial worry and loneliness remained substantively unchanged.

In exploratory models including age and disease severity, older patients had poorer psychological health than younger patients $(\gamma=0.27, \mathrm{SE}=0.10, p=.0089)$, and older spouses also tended to have poorer psychological health $(\gamma=0.15, \mathrm{SE}=0.09, p=.11)$, with no significant difference between patient and spouse estimates $(t=0.96, p=.34)$. For loneliness, there was a statistically significant interaction with patient age such that the within-patient slope of loneliness was flatter with older age $(\gamma=-0.04, \mathrm{SE}=0.02, p=.029$ ), and there was a tendency for the between-patient slope of loneliness to interact with age in the same way $(\gamma=-0.09, \mathrm{SE}=0.05, p=.08$ ). Although not statistically significant, the between-person interaction between age and loneliness was in the opposite direction for older spouses $(\gamma=0.07, \mathrm{SE}=0.05, p=.14)$ and significantly different from the interaction effect for patients $(t=2.33, p=.022)$. See estimated between-person loneliness slopes in Figure 2. When loneliness was relatively low, only older patients had poorer psychological health. Older patients also had the poorest psychological health at higher levels of loneliness, but younger patients and older spouses (who were similarly affected) had poorer psychological health, and younger spouses had the best psychological health.

For financial worry, there were no statistically significant interactions with age for either patients or spouses (all $p>.37$ ). For patients, disease severity did not interact with loneliness. However, the within-patient slope of financial worry was steeper for patients with 
less severe disease $(\gamma=0.07, \mathrm{SE}=0.03, p=0.01)$. See estimated within-person loneliness slopes in Figure 3.

Finally, exploratory analyses tested whether gender, which was a covariate in Model 4, could account for these findings. However, adding interactions with gender did not yield any statistically significant effects.

\section{Discussion}

Socioemotional selectivity theory predicts that as time remaining in life decreases, resources and goals that can be realized in the present moment, particularly close social relationships, become more important. Conversely, resources and goals that are focused on the future or take time to realize become less important. The present study employed longitudinal dyadic analyses to test predictions of the theory in ALS patients and their spouses. Contrary to the first hypothesis of the study, patients and spouses did not differ in their levels of loneliness (which reflects concern over the adequacy of close social relationships), nor in their levels of financial worry (which reflects concern over the adequacy of financial resources). Consistent with this finding, in a survey of stressors experienced by ALS patients $(n=66)$ and spouses $(n=61)$, equal numbers of patients and spouses endorsed loneliness. More spouses than patients endorsed worries about the future, although this was not a statistically significant difference (Trail, Nelson, Van, Appel, \& Lai, 2004).

However, supporting the second hypothesis, loneliness and financial worry affected patients and spouses differently. Most of the evidence supporting socioemotional selectivity theory demonstrates differences in goals and motivations between people approaching the end of life and those with more life remaining, without considering the consequences of these differences. However, the implications of socioemotional shifts for psychological health are important. Among patients with metastatic breast cancer, more goals consistent with socioemotional shifts were associated with better psychological health (Sullivan-Singh et al., 2015). The present investigation takes this extension of the theory one step further, finding that concerns in domains relevant to socioemotional selectivity (close social connection vs. finances) had differential effects on psychological health based on both life-limiting disease and age.

Higher loneliness both as individual differences (between people) and changes over time (within people) was associated with poorer psychological health for both dyad members. Loneliness effects were larger for patients than spouses both between $(\gamma=3.24$ vs. 2.80) and within people ( $\gamma=1.17$ vs. 0.93 ); however, these differences were not statistically significant. Patients and spouses did differ in the interaction between age and loneliness. For spouses, the effect of loneliness on psychological health was stronger with older age, consistent with the predictions of socioemotional selectivity theory: Although spouses did not have ALS, older spouses were also closer to the end of life, which should make them more sensitive to close social resources and any perceived lack thereof.

The interaction between age and loneliness in patients was partially driven by the generally poorer psychological health for older patients across all levels of loneliness (see Figure 2). It 
is possible that the combination of ALS and older age led these patients to be psychologically sensitive even to low levels of loneliness. Alternatively, older patients with ALS may have other, more important influences on psychological health. This interaction was found at the between-person level, suggesting that age moderates the effects of longerterm loneliness to a greater degree than it does effects of fluctuations in loneliness. The finding that older patients had poorer psychological health than younger patients is contrary to the general finding that older people report less negative affect and higher life satisfaction than younger people (e.g., Charles, Reynolds, \& Gatz, 2001). However, within older age, there is a downturn in well-being (e.g., from a peak in life satisfaction around age 75;

Segerstrom et al., 2016). Patient age ranged from 33 years to 82 years. Older patients may have experienced effects of loneliness and ALS on psychological health on top of a normative downturn; however, absent premorbid data, this is speculation. This finding awaits replication.

Financial worry had more limited relationships with psychological health. Consistent with socioemotional selectivity theory, financial worry affected the psychological health of spouses $(\gamma=1.47)$ to a greater degree than patients $(\gamma=0.12)$. The effect of financial worry on patients' psychological health depended on the stage of their disease: only for patients with less advanced disease did increases in financial worry result in decreases in psychological health (see Figure 3). Disease severity may affect a patient's sense of the nearness of death and influence the value they place on future-oriented resources such as money. This interaction was found at the within-person level, suggesting that increases or decreases in financial worry differentially affect patients at different stages of the disease, whereas longer-term individual differences in financial worry were unrelated to psychological health.

These findings provide more evidence that socioemotional selectivity yields psychological benefit when people are closer to the end of life (see also Sullivan-Singh et al., 2015). More evidence across different health challenges and with different kinds of caregivers (e.g., spouses vs. children) is still needed. Although socioemotional selectivity theory has not been applied in health psychology settings, it has the potential to improve understanding of how different resources contribute differently to psychological health for patients, family, and caregivers at different stages of disease and of life and to guide interventions and support. One size may not fit all.

Advantages of the present study included the longitudinal, dyadic assessments, which allowed for examination of couples' stable individual differences and fluctuations over time. In addition, the multi-site sample was relatively large for a study of ALS, providing adequate power to detect medium effect sizes. There are also some limitations to this study. First, only total scores were available in the archived database, and so scale reliabilities for the analytic sample could not be calculated, nor could between-person and within-person reliabilities (Cranford et al., 2006). The measure of loneliness had 4 items and the measure of financial worry had 1, potentially giving loneliness a predictive advantage because it would be expected to have better reliability. However, reliability is higher than the ICC (in this case, .66-.67) when reliable within-person variance is greater than 0 , and so the item was adequately reliable. Second, deaths during data collection affected the number of 
observations for 41 dyads. Such deaths could bias, for example, estimation of the effects of passage of time on psychological health. However, dyads completed, on average, 4-5 of the 7 possible interviews. Third, these data were collected in the 1980s, but there has been little change in the treatment of or prognosis for ALS. The drug riluzole may increase life expectancy by $2-3$ months, but multidisciplinary care has proven at least equally advantageous for patient well-being and survival (van Es et al., 2017). All three sites in the present study provided multidisciplinary care. Fourth, the sample was diverse in socioeconomic status but not in race. Although ALS is somewhat more prevalent in populations with European ancestry, it does affect people with other ancestries, who were underrepresented in the present study (van Es et al., 2017).

In conclusion, the present study provides good support for the predictions of socioemotional selectivity theory in a strong test of the theory. By studying dyads in which one member was approaching end of life, the effects of a shorter time remaining in life could be isolated from general effects of coping with disease such as reminders of mortality and financial and social challenges. Indeed, patients and spouses reported similar mean levels of concern in social and financial domains, but they were not equally affected by these domains: Approaching the end of life reduced the impact of financial concerns and increased the impact of social concerns on psychological health. The importance of socioemotional resources not only changes as the end of life approaches, but also influences how these resources impact psychological health.

\section{Acknowledgements}

The de-identified data from the Seattle ALS Patient Project were provided to Drs. Segerstrom and Kasarskis by Al Hillel, M.D., and Rhoda Walters, project investigators.

Funding

This work was supported by the National Institute on Aging (K02-AG033629).

\section{References}

Aiken LS, \& West SG (1991). Multiple regression: Testing and interpreting interactions. Newbury Park, CA: Sage.

Beck AT, Steer RA, \& Carbin MG (1988). Psychometric properties of the Beck Depression Inventory: Twenty-five years of evaluation. Clinical Psychology Review, 8, 77-100. DOI: 10.1016/0272-7358(88)90050-5

Beck AT, Ward CH, Mendelson M, Mock J, \& Erbaugh J (1961). An inventory for measuring depression. Archives of General Psychiatry, 4, 561-571. DOI: 10.1001/ archpsyc.1961.01710120031004 [PubMed: 13688369]

Beck AT, Weissman A, Lester D, \& Trexler L (1974). The measurement of pessimism: The hopelessness scale. Journal of Consulting and Clinical Psychology, 42, 861-865. DOI: 10.1037/ h0037562 [PubMed: 4436473]

Brown GK, Beck AT, Steer RA, \& Grisham JR (2000). Risk factors for suicide in psychiatric outpatients: a 20-year prospective study. Journal of Consulting and Clinical Psychology, 68, 371377. [PubMed: 10883553]

Carstensen LL, \& Fredrickson BL (1998). Influence of HIV status and age on cognitive representations of others. Health Psychology, 17, 494-503. DOI: 10.1037//0278-6133.17.6.494 [PubMed: 9848799] 
Carstensen LL, Fung HH, \& Charles ST (2003). Socioemotional selectivity theory and the regulation of emotion in the second half of life. Motivation and Emotion, 27, 103-123. DOI: 10.1023/ a: 1024569803230

Carstensen LL, Isaacowitz DM, \& Charles ST (1999). Taking time seriously: A theory of socioemotional selectivity. American Psychologist, 54, 165-181. DOI: 10.1037//0003-066x.54.3.165 [PubMed: 10199217]

Charles ST, Reynolds CA, \& Gatz M (2001). Age-related differences and change in positive and negative affect over 23 years. Journal of Personality and Social Psychology, 80, 136-151. [PubMed: 11195886]

Cohen P, Cohen J, Aiken LS, \& West SG (1999). The problem of units and the circumstance for POMP. Multivariate Behavioral Research, 34, 315-346. DOI: 10.1207/s15327906mbr3403_2

Cohen S, Kamarck T, \& Mermelstein R (1983). A global measure of perceived stress. Journal of Health and Social Behavior, 24, 385-396. DOI: 10.2307/2136404 [PubMed: 6668417]

Cohen S, \& Williamson GM (1988). Perceived stress in a probability sample of the United States In Spacapan S \& Oskamp S (Eds.), The Social Psychology of Health (pp. 31-67). Newbury Park, CA: Sage.

Cranford JA, Shrout PE, Iida M, Rafaeli E, Yip T, \& Bolger N (2006). A procedure for evaluating sensitivity to within-person change: Can mood measures in diary studies detect change reliably? Personality and Social Psychology Bulletin, 32, 917-929. DOI: 10.1177/0146167206287721 [PubMed: 16738025]

Emmons RA (1986). Personal strivings: An approach to personality and subjective well-being. Journal of Personality and Social Psychology, 51, 1058-1068. DOI: 10.1037//0022-3514.51.5.1058

Fung HH, \& Carstensen LL (2004). Motivational changes in response to blocked goals and foreshortened time: Testing alternatives to socioemotional selectivity theory. Psychology and Aging, 19, 68-78. DOI: 10.1037/0882-7974.19.1.68 [PubMed: 15065932]

Garcia NE, Morey JN, Kasarskis E, \& Segerstrom SC (2017). Purpose in life in ALS patient-caregiver dyads: A multilevel, longitudinal analysis. Health Psychology, 36, 1092-1104. DOI: 10.1037/ hea0000507 [PubMed: 28541074]

Gauthier A, Vignola A, Calvo A, Cavallo E, Moglia C, Sellitti L, ... \& Chio, A. (2007). A longitudinal study on quality of life and depression in ALS patient-caregiver couples. Neurology, 68, 923-926. DOI: 10.1212/01.wnl.0000257093.53430.a8 [PubMed: 17372127]

Hillel AD, Miller RM, Yorkston K, McDonald E, Norris FH, \& Konikow N (1989). Amyotrophic Lateral Sclerosis Severity Scale. Neuroepidemiology, 8, 142-150. DOI: 10.1159/000110176 [PubMed: 2725806]

Kendall PC, Hollon SD, Beck AT, Hammen CL, \& Ingram RE (1987). Issues and recommendations regarding use of the Beck Depression Inventory. Cognitive Therapy and Research, 11, 289-299. DOI: $10.1007 / \mathrm{BF} 01186280$

King LA, Richards JH, \& Stemmerich E (1998). Daily goals, life goals, and worst fears: Means, ends, and subjective well-being. Journal of Personality, 66, 713-744. DOI: 10.1111/1467-6494.00030 [PubMed: 9802231]

Laurenceau JP, \& Bolger N (2013). Intensive longitudinal methods: An introduction to diary and experience sampling research. New York: Guilford.

Lo C, Hales S, Braun M, Rydall AC, Zimmermann C, \& Rodin G (2013). Couples facing advanced cancer: Examination of an interdependent relational system. Psycho-Oncology, 22, 2283-2290. DOI: 10.1002/pon.3289 [PubMed: 23630165]

McDonald ER, Wiedenfeld SA, Hillel A, Carpenter CL, \& Walter RA (1994). Survival in amyotrophic lateral sclerosis: the role of psychological factors. Archives of Neurology, 51, 17-23. DOI: 10.1001/archneur.1994.00540130027010 [PubMed: 8274106]

McGregor I, \& Little BR (1998). Personal projects, happiness, and meaning: on doing well and being yourself. Journal of Personality and Social Psychology, 74, 494-512. DOI: 10.1037//0022-3514.74.2.494 [PubMed: 9491589]

Meyer TJ, \& Mark MM (1995). Effects of psychosocial interventions with adult cancer patients: a meta-analysis of randomized experiments. Health Psychology, 14, 101-108. DOI: 10.1037/0278-6133.14.2.101 [PubMed: 7789344] 
Moeller J (2015). A word on standardization in longitudinal studies: don't. Frontiers in Psychology, 6, Article 1389. DOI: 10.3389/fpsyg.2015.01389

Pinquart M, \& Silbereisen RK (2006). Socioemotional selectivity in cancer patients. Psychology and Aging, 21, 419-423. DOI: 10.1037/0882-7974.21.2.419 [PubMed: 16768587]

Rabkin JG, Wagner GJ, \& Del Bene M (2000). Resilience and distress among amyotrophic lateral sclerosis patients and caregivers. Psychosomatic Medicine, 62, 271-279. DOI: 10.1097/00006842-200003000-00020 [PubMed: 10772408]

Riediger M, Schmiedek F, Wagner GG, \& Lindenberger U (2009). Seeking pleasure and seeking pain: Differences in prohedonic and contra-hedonic motivation from adolescence to old age. Psychological Science, 20, 1529-1535. DOI: 10.1111/j.1467-9280.2009.02473.x [PubMed: 19891749]

Roach AR, Averill AJ, Segerstrom SC, \& Kasarskis EJ (2009). The dynamics of quality of life in ALS patients and caregivers. Annals of Behavioral Medicine, 37, 197-206. DOI: 10.1007/ s12160-009-9092-9 [PubMed: 19350337]

Rook KS (1984). Research on social support, loneliness, and social isolation: Toward an integration. Review of Personality and Social Psychology, 5, 239-264. DOI: 10.1007/978-94-009-5115-0_14

Routasalo PE, Savikko N, Tilvis RS, Strandberg TE, \& Pitkälä KH (2006). Social contacts and their relationship to loneliness among aged people - a population-based study. Gerontology, 52, 181187. DOI: $10.1159 / 000091828$ [PubMed: 16645299]

Russell DW, Cutrona CE, McRae C, \& Gomez M (2012). Is loneliness the same as being alone? The Journal of Psychology, 146, 7-22. DOI: 10.1080/00223980.2011.589414 [PubMed: 22303609]

Russell DW, Peplau LA, \& Cutrona CE (1980). The revised UCLA Loneliness Scale: Concurrent and discriminant validity evidence. Journal of Personality and Social Psychology, 39, 472-480. DOI: 10.1037//0022-3514.39.3.472 [PubMed: 7431205]

Segerstrom SC, Jones AC, Scott AB, \& Crofford LJ (2016). Daily goals and psychological well-being in midlife and older women: Physical pain interacts with goal conflict. Research in Human Development, 13, 328-341. DOI: 10.1080/15427609.2016.1234306 [PubMed: 28603467]

Silverman RA, \& Kennedy LW (1985). Loneliness, satisfaction and fear of crime: A test for nonrecursive effects. Canadian Journal of Criminology, 27, 1-13.

Sörensen S, Pinquart M, \& Duberstein P (2002). How effective are interventions with caregivers? An updated meta-analysis. The Gerontologist, 42, 356-372. DOI: 10.1093/geront/42.3.356 [PubMed: 12040138]

Sullivan-Singh SJ, Stanton AL, \& Low CA (2015). Living with limited time: Socioemotional selectivity theory in the context of health adversity. Journal of Personality and Social Psychology, 108, 900-916. DOI: 10.1037/a0039047 [PubMed: 25984789]

Trail M, Nelson ND, Van JN, Appel SH, \& Lai EC (2004). Major stressors facing patients with amyotrophic lateral sclerosis (ALS): a survey to identify their concerns and to compare with those of their caregivers. Amyotrophic Lateral Sclerosis and Other Motor Neuron Disorders, 5, 40-45. DOI: 10.1080/14660820310016075 [PubMed: 15204023]

van Es MA, Hardiman O, Chio A, Al-Chalabi A, Pasterkamp RJ, Veldink JH, \& van den Berg LH (2017). Amyotrophic lateral sclerosis. Lancet, 390, 2084-2098. DOI: 10.1016/

S0140-6736(17)31287-4 [PubMed: 28552366]

Psychol Health. Author manuscript; available in PMC 2020 October 01. 


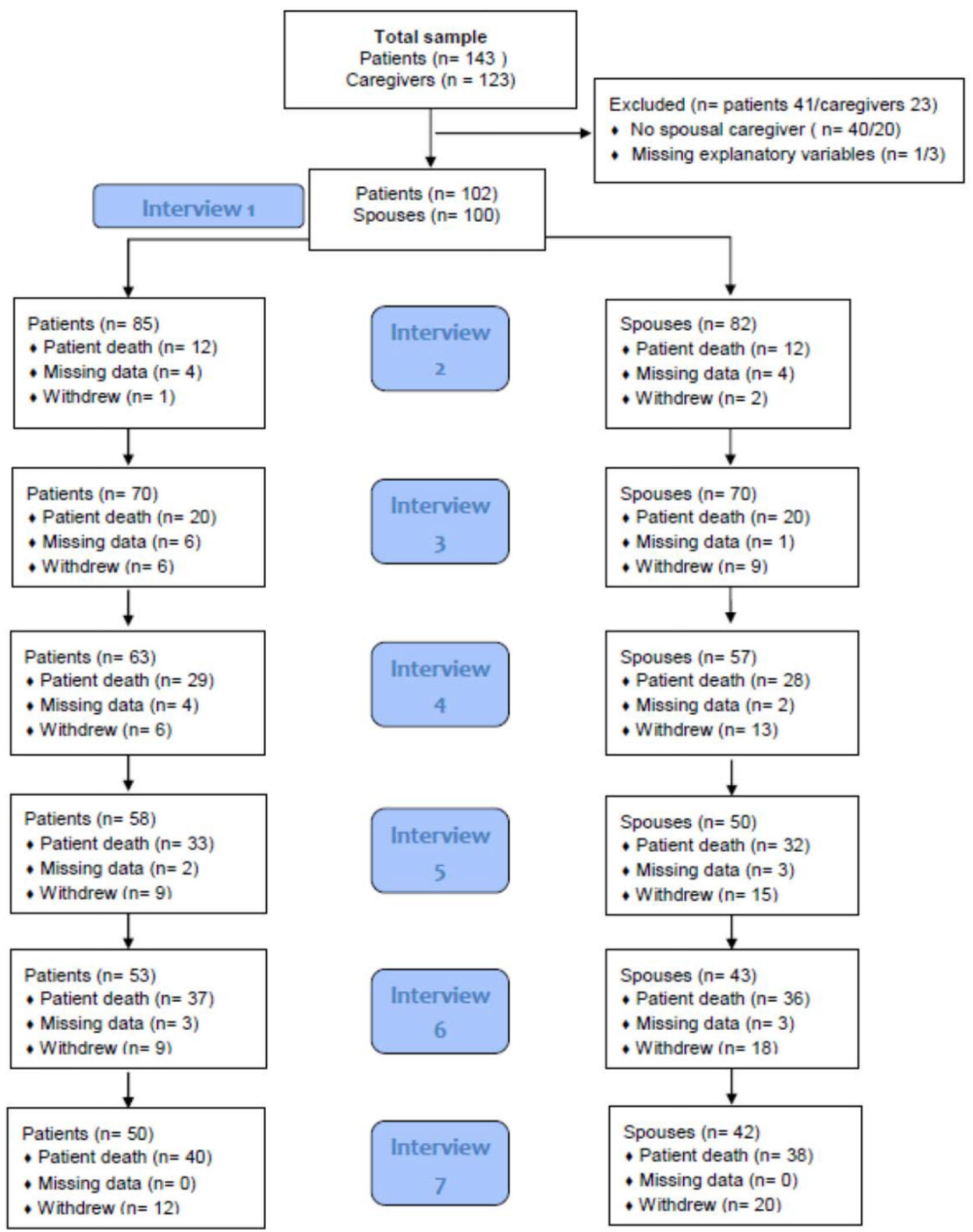

Figure 1.

Diagram showing reasons for exclusion and missingness across the study. Numbers for patient death and withdrawal are cumulative; numbers for missing data are specific to that interview. 


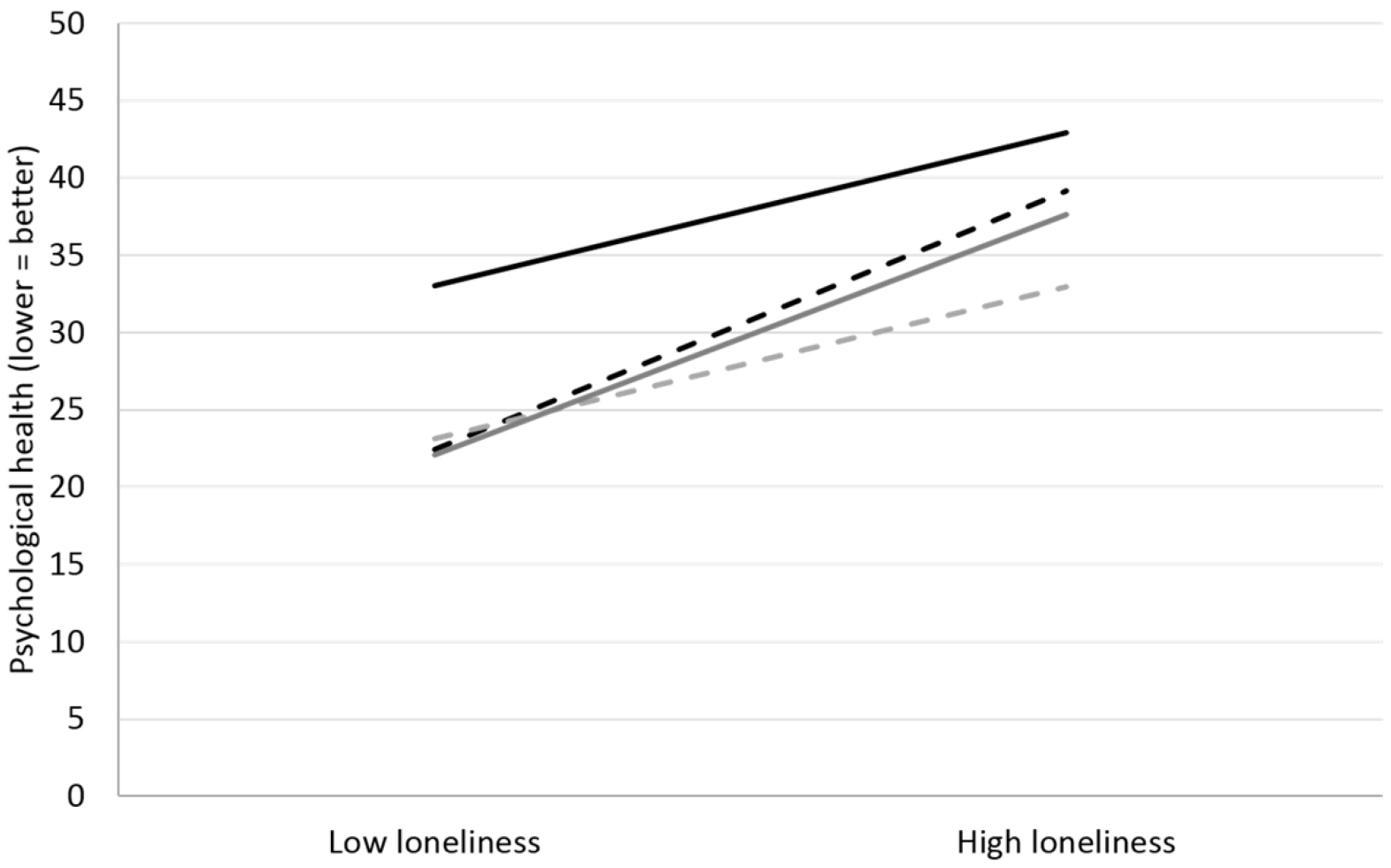

- - Younger patients —Older patients - - Younger spouses —Older spouses

Figure 2.

Model-estimated between-person loneliness slopes ( \pm 2 points) for younger ( -10 years) and older (+ 10 years) patients and spouses. Intervals represent approximately \pm 1 SD for loneliness and age. 


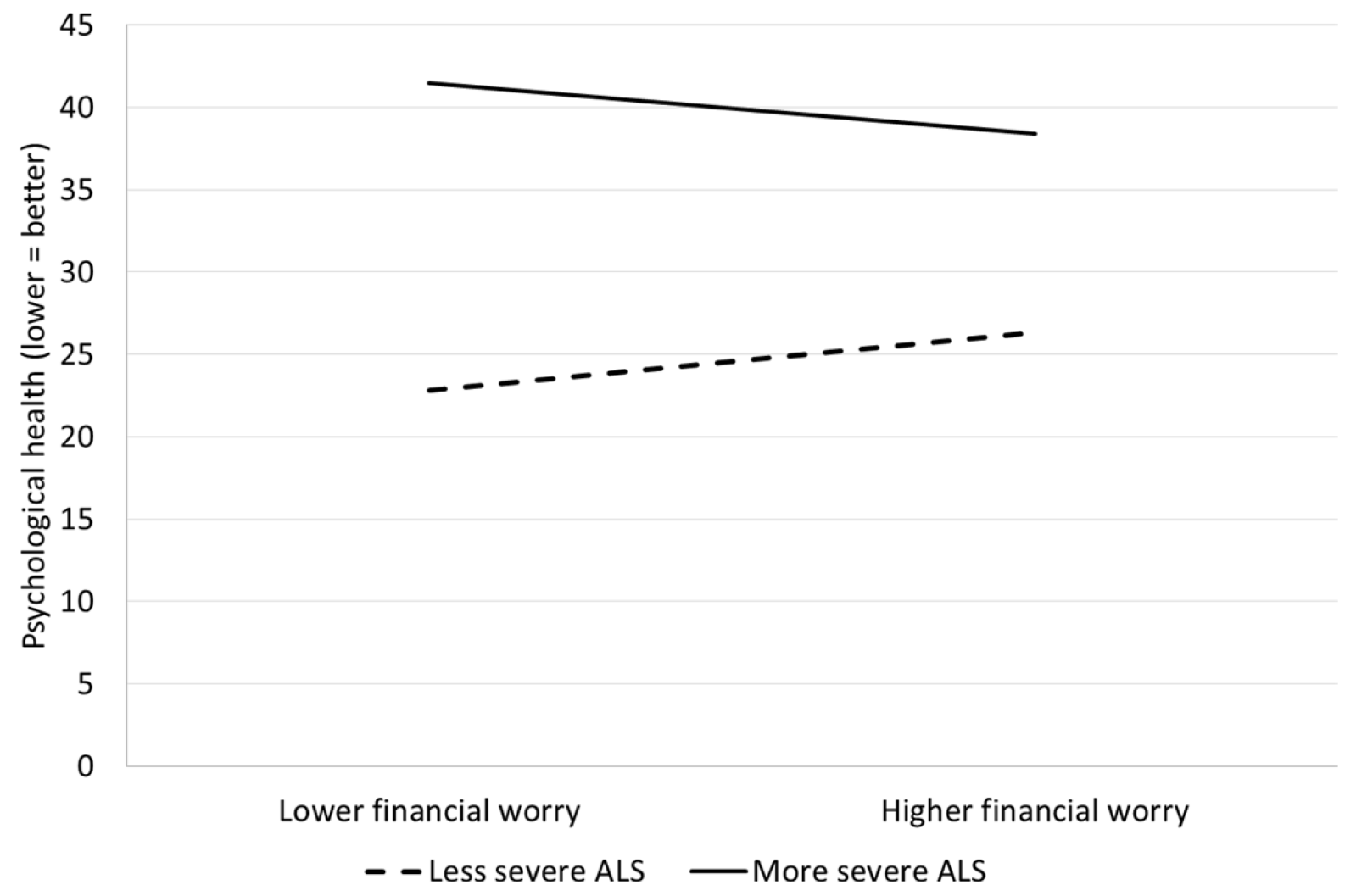

Figure 3.

Model-estimated within-person financial worry slopes ( \pm 2.5 points $)$ for patients with less severe ( -10 ALSS points) and more severe disease (+10 ALSS points). Intervals represent approximately \pm 1 SD for financial worry and disease severity. 
Table 1.

Demographic characteristics of patients and spouses at baseline

\begin{tabular}{|c|c|c|c|}
\hline & & Patient Mean (SD) or \% (n/102) & Spouse Mean (SD) or $\%(\mathrm{n} / 100)$ \\
\hline Age (years) & & $60.3(11.7)$ & $57.9(12.5)$ \\
\hline \multirow[t]{2}{*}{ Gender } & Male & $73.5(75)$ & $26.0(26)$ \\
\hline & Female & $26.5(27)$ & $74.0(74)$ \\
\hline \multirow[t]{4}{*}{ Race } & White/Caucasian & $96.1(98)$ & $96.0(96)$ \\
\hline & Black/African-American & $2.0(2)$ & $2.0(2)$ \\
\hline & Asian-American & $1.0(1)$ & $1.0(1)$ \\
\hline & Native American & $1.0(1)$ & $1.0(1)$ \\
\hline Highest & Grade $1-6$ & $0.0(0)$ & $1.0(1)$ \\
\hline \multirow[t]{8}{*}{ Education } & Grade 7-9 & $5.9(6)$ & $9.0(9)$ \\
\hline & Grade $10-12$ & $34.3(35)$ & $37.0(37)$ \\
\hline & GED & $4.9(5)$ & $3.0(3)$ \\
\hline & Some college & $25.5(26)$ & $29.0(29)$ \\
\hline & College graduate & $12.8(13)$ & $7.0(7)$ \\
\hline & Some post-graduate & $5.9(6)$ & $7.0(7)$ \\
\hline & Master's degree & $5.9(6)$ & $4.0(4)$ \\
\hline & Doctoral degree & $4.9(5)$ & $3.0(3)$ \\
\hline ALSS & Total score & $24.5(8.4)$ & \\
\hline Respiratory & On (any duration) & $11.8(12)$ & \\
\hline \multirow[t]{2}{*}{ support } & Not on & $79.4(81)$ & \\
\hline & Started during study & $8.8(9)$ & \\
\hline
\end{tabular}

Note. ALSS $=$ ALS Severity Scale. An ALSS score of 24.5 is considered 'moderate' disease. 
Table 2.

Descriptives for and correlations among Level 2 (mean) variables among patients $(\mathrm{N}=102$; below diagonal) and spouses $(\mathrm{N}=100$; above diagonal)

\begin{tabular}{|l|r|c|c|c|c|c|c|}
\hline \multicolumn{1}{|c|}{ Scale (scale range) } & Mean (SD) & Loneli-ness & Financial worry & $\begin{array}{l}\text { Psycho-logical } \\
\text { health }\end{array}$ & Age & Gender & ALSS \\
\hline \multicolumn{1}{|c|}{ Mean (SD) } & & $8.2(1.6)$ & $5.0(2.6)$ & $28.6(11.5)$ & $57.9(12.5)$ & $74 \%$ & $22.3(7.9)$ \\
\hline Loneliness (4-16) & $7.7(1.8)$ & - & .09 & $.46^{* *}$ & .05 & -.16 & -.10 \\
\hline Financial worry (1-10) & $4.7(2.7)$ & .08 & - & $.37^{* *}$ & -.06 & .10 & $-.20^{*}$ \\
\hline Psychological health (0-100) & $34.5(13.7)$ & $.45^{* *}$ & .07 & - & .15 & .08 & $-.20^{*}$ \\
\hline Age (years) & $60.3(11.7)$ & -16 & -.07 & $.24^{*}$ & - & -.19 & .09 \\
\hline Gender (1 female) & $26 \%$ & -.10 & .00 & .09 & .00 & - & .13 \\
\hline ALSS (4-40) & $22.3(8.0)$ & -.06 & -.08 & -.18 & .05 & -.11 & - \\
\hline
\end{tabular}

* $p<.05$

**

$p \leq .0001$

Note. Lower scores on psychological health indicate better health; higher scores on the ALSS indicate less severe disease. 
Table 3.

Dyadic models predicting psychological health (lower $=$ better)

\begin{tabular}{|c|c|c|c|c|c|}
\hline & Range & $\gamma(\mathbf{S E})$ & $\gamma(\mathrm{SE})$ & $\gamma(\mathrm{SE})$ & $\gamma(\mathrm{SE})$ \\
\hline Fixed Effects & & 1 & 2 & 3 & 4 \\
\hline Patient intercept & $0-100$ & $33.58(1.25)$ & 34.75 (1.37) & $34.37(1.23)$ & See footnote \\
\hline \multicolumn{6}{|l|}{ Patient (within) } \\
\hline Time & $1-7$ & & $0.55^{*}(0.24)$ & $0.27(0.21)$ & $0.28(0.21)$ \\
\hline Financial worry & $0-10$ & & & $0.11(0.19)$ & $0.12(0.19)$ \\
\hline Loneliness & $4-16$ & & & $1.17^{* *}(0.27)$ & $1.22^{* *}(0.28)$ \\
\hline \multicolumn{6}{|l|}{ Patient (between) } \\
\hline Financial worry & $0-10$ & & & $0.12(0.44)$ & $0.12(0.19)$ \\
\hline Loneliness & $4-16$ & & & $3.24^{* *}(0.65)$ & $3.14^{* *}(0.65)$ \\
\hline Spouse intercept & $0-100$ & $28.57(1.14)$ & $29.3(1.21)$ & $29.08(1.03)$ & See footnote \\
\hline \multicolumn{6}{|l|}{ Spouse (within) } \\
\hline Time & & & $0.32+(0.18)$ & $0.31(0.17)$ & $0.31(0.17)$ \\
\hline Financial worry & $0-10$ & & & $0.08(0.16)$ & $0.08(0.16)$ \\
\hline Loneliness & $4-16$ & & & $0.93^{* *}(0.20)$ & $0.92^{* *}(0.20)$ \\
\hline \multicolumn{6}{|l|}{ Spouse (between) } \\
\hline Financial worry & $0-10$ & & & $1.47^{*}(0.38)$ & $1.43^{*}(0.38)$ \\
\hline Loneliness & $4-16$ & & & $2.80^{* *}(0.61)$ & $3.03^{* *}(0.61)$ \\
\hline \multicolumn{6}{|l|}{ Random Effects } \\
\hline Patient intercept & & 93.5 & 26.8 & 44.5 & 80.0 \\
\hline Spouse intercept & & 97.5 & 61.0 & 36.6 & 58.9 \\
\hline Patient loneliness slope & & & & 1.7 & 1.7 \\
\hline Patient-spouse intercept covariance & & 11.4 & -1.5 & -6.6 & -0.1 \\
\hline Patient intercept-slope covariance & & & & -1.8 & 0.5 \\
\hline Spouse intercept-patient slope covariance & & & & -0.6 & 0.2 \\
\hline AIC & & 6653.6 & 6653.9 & 6433.6 & 6414.2 \\
\hline \multicolumn{6}{|l|}{$*<.05$} \\
\hline$p<.0001$ & & & & & \\
\hline
\end{tabular}

Note. Model 4, which adjusted for study site and gender, yielded site-specific intercepts for patients and spouses. There was a significant effect of site for patients $(\mathrm{F}(2,101)=5.13, p=.0076)$ but not spouses $(\mathrm{F}(2,99=1.41, p=.25)$. Patients in San Francisco had the best psychological health, followed by Seattle, followed by Philadelphia. There was a significant effect of gender for spouses $(\mathrm{F}(1,99)=4.46, p=.037)$ but not patients $(\mathrm{F}(1,101)=1.37, p=.24)$. Male spouses had poorer psychological health than female spouses.

Model 3 was repeated for patients and spouses using the separate components of the psychological health score (depression, hopelessness, and stress). All statistically significant effects of loneliness and financial worry reported above for the composite were present for each component, with one exception: the within-person effect of loneliness in spouses was not statistically significant when the outcome was hopelessness $(p=.15)$. All statistically significant effects withstood Bonferroni adjustment $(a=.05 / 3)$. No new statistically significant effects (i.e., not found in the original model) emerged with or without Bonferroni adjustment. 